ISBN 978-93-84422-77-6

2017 International Conference on Innovations in Engineering \& Technology

(ICCET-2017)

Dubai (UAE)May 10-11, 2017

\title{
H-I-L Analysis of Smart Solar Roof
}

\author{
Fesmi Abdul Majeed ${ }^{1}$, Ibrahim Ali Alhammadi ${ }^{2}$, Mohammed Ahmed AlSereidi ${ }^{2}$ and Ebrahim Ali \\ AlDhanhani $^{2}$, Khalid Saeed Alnaqbi ${ }^{2}$, Obaid Ali Alzaabi ${ }^{2}$ \\ ${ }^{1}$ Faculty, Higher College of Technology, Fujairah, UAE \\ ${ }^{2}$ Student, Higher College of Technology, Fujairah, UAE
}

\begin{abstract}
This paper presents an innovative and industry viable design of HIL solar shade. The shade is designed to automatically expand and retract, is self sustainable and utilizes clean energy. This paper discusses the design, the inbuilt programming logic and the results of a full functional prototype testing at the Higher Colleges of Technology, Fujairah, UAE.
\end{abstract}

Keywords: Flexible Solar Panel, Automatic roof, Shade

\section{Introduction}

Growing environmental awareness and urban landscaping architecture policies directly urge the necessity for a Smart eco-friendly roofing scheme. Hence, temporary shelters have gained increasing popularity in recent times, and the number of situational applications for these shelters continue to grow. Typically, these temporary shelters include assembled framework structures that collapse into a compact stored state and expand into an erected state covering a larger surface area. These shelters provide shade and protection from sun, and rain. However, an industrially viable auto powered expandable roofing system which could be permanently installed with low maintenance requirements is not yet developed, though the requirement and time is high.

We present in this paper a design for such an industrially manufacturing friendly design which is also selfreliant in terms of energy consumption and auto expandable thus striking a balance between the urban landscaping policy requirements as well as eco and green environment utilizing clean energy. In order to meet the objectives of the innovative design the following points have been carefully considered and incorporated:

a. Simple and viable, industrially manufacture-able scalable compact structural framework design.

b. Driven by Wind or Solar energy.

c. Automatic object and weather sensor system with timed feedback controller.

d. Weather resistant and durable roofing material

1. Community survey

The innovative design presented in this paper is a flexible solar roofing system that might be a big help in building investment. It consists of the essential components: which are flexible solar panel, LDR sensor, proximity sensor, rechargeable battery and linear actuator. Figure 1 displays the survey results on this design by employees at Ministry of public work of UAE. 


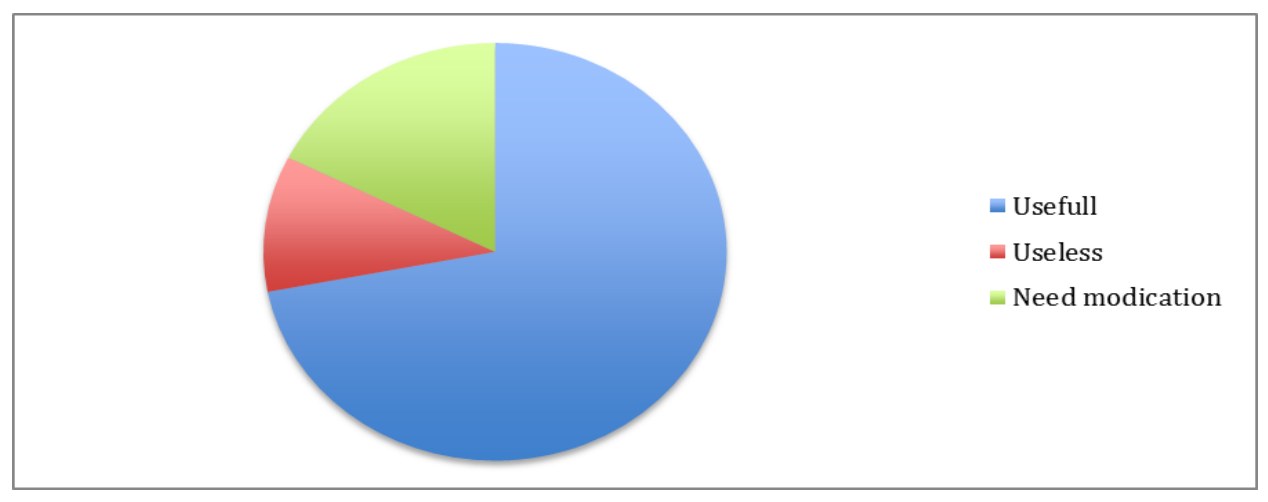

Fig. 1: HIL Smart Roof Community survey

The selected site is in Fujairah, one of the emirates, which is interested in youth investment and innovations; It's the ministry of public works. This design, once industrially manufactured and implemented will promote comfort facilities for the residents, buildings and clean energy. Moreover, this design is innovative and practical due to the efficient integration of two functional elements; the solar panel and auto expanding durable roof.

\section{Design study}

The smart solar roof working and design is explained in this section.

The prominent innovative features are the flexible solar sheet from PowerfilmTM which consists of thin PV filaments coated on to durable, weather and water resistant roofing material [3]. The result is a fully flexible, rollable solar panel sheet. This sheet is rolled into very compact size using the roller blind technology.

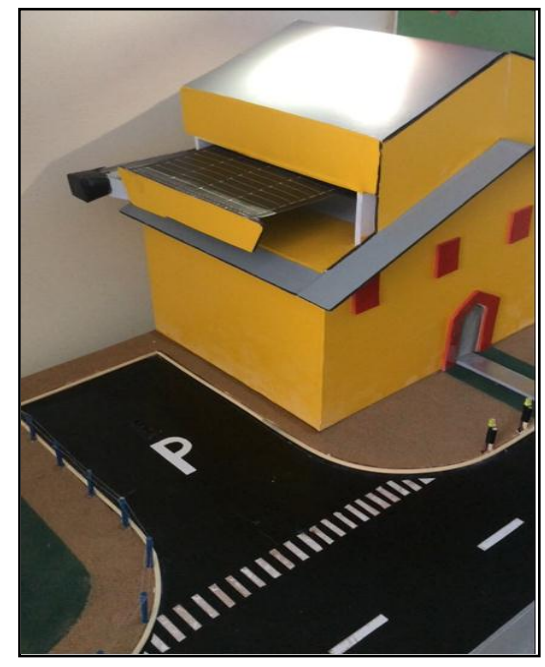

Fig. 2: HIL Smart roof Partial expansion

The expansion and closing of the roof is prompted by linear actuator. The linear actuator triggers the expansion or retraction of antenna like segmented rods attached at the sides of the rollable solar panel roof. The linear actuator is triggered by programmed Arduino (programmable micro controller kit) which receives feedback from two sensors.

The LDR sensor detects presence of high solar radiation /intensity and is placed on the roof in the prototype (refer Figure 2). The proximity sensor is used to detect the presence of object which requires shading; in the prototype (Figure 2) it is placed below the Parking area. 
TABLE I: HIL Experimental Case Study

\begin{tabular}{lllll}
\hline \hline Case & 1 & 2 & 3 & 4 \\
\hline Sunny & No & No & Yes & Yes \\
Object & No & Yes & No & Yes \\
$\begin{array}{l}\text { Solar Roof } \\
\text { Expansion }\end{array}$ & No & No & Partial & Full \\
\hline \hline
\end{tabular}

Four separate cases are considered (Refer Table 1) to develop the programming and triggering of the linear actuator. First case - where the solar shade needn't expand is when the proximity sensor and LDR return negative - implying no object and no high solar radiation intensity. The second case which doesn't require solar shade to expand is when the LDR returns negative - in this case there is no high solar radiation and hence the shade needn't expand even if object is present.

The third case requires partial expansion of the solar shade (Figure 2) - this is to ensure the solar shade gets recharged as required for its battery. This special case is only when a high solar radiation intensity is perceived by the LDR sensor, even though, the proximity sensor gives negative feedback, due to lack of object. the partial expansion ensures the solar roof remains mostly hidden.

The fourth and last condition when the solar roof expands full (Figure 3) is when both the sensors give a positive feedback and its necessary for the roof to remain expanded sheltering the object. These conditions are triggered only after a specific time lag so as to ensure the object and light intensity are present for a while and are not passing by.

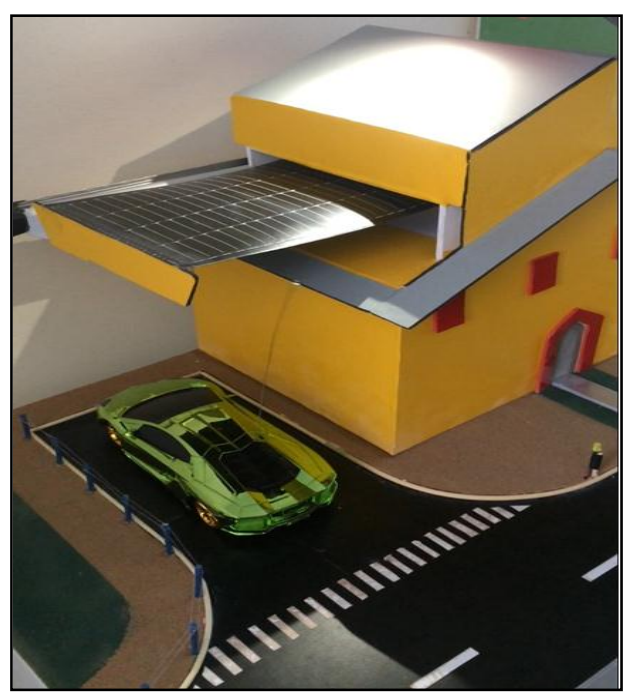

Fig. 3: HIL Smart Roof Full expansion

\section{Conclusion}

To conclude, this design is very suitable for the climatic conditions present in UAE and any Middle east region, as the climate here is marked by predominant clear skies and high solar intensity. Future design improvements will incorporate Internet of Things technology and utilizing the excess energy stored in battery for any electric appliance. 


\section{References (This is "Header 1" style)}

[1] .D. Carlsonb, J. G. (2010). An integrated empirical and modeling methodology for analyzing solar reflective roof technologies on commercial buildings. Building and Environment , 45 (2), 453-460.

https://doi.org/10.1016/j.buildenv.2009.07.001

[2] Staying Cool and Connected During Hajj Under a Solar-Powered Umbrella. (n.d.). Retrieved from City Lab : http://www.citylab.com/navigator/2016/08/staying-cool-and-connected-during-hajj-under-a-solar-poweredumbrella/496892/

[3] Rollable Solar Panel

http://www.powerfilmsolar.com/products/?rollable_solar_panels\&show=category\&productCategoryID=6580\&produc tCategoryIDs $=6578,6580$ 